Article

\title{
Fatty Acids Variation in Seed of Eucommia ulmoides Populations Collected from Different Regions in China
}

\author{
Qingxin Du ${ }^{1}{ }^{10}$, Lu Wang ${ }^{1}$, Panfeng Liu ${ }^{1}$, Jun Qing ${ }^{1}$, Caowen Sun ${ }^{2}$, Zhiqiang Sun ${ }^{1}$ and \\ Hongyan $\mathrm{Du}^{1, *}$ \\ 1 Non-Timber Forest R\&D Center, Chinese Academy of Forestry, Zhengzhou 450003, China; \\ duqingxin20102325@163.com (Q.D.); wanglu181716@163.com (L.W.); lpf11784247@163.com (P.L.); \\ 18247167605@163.com (J.Q.); zq_sun@paulownia.ac.cn (Z.S.) \\ 2 Key Laboratory for Silviculture and Conservation, Ministry of Education, Beijing Forestry University, \\ Beijing 100083, China; a958074127@163.com \\ * Corresponding: dhy515@caf.ac.cn; Tel.: +86-371-86139032
}

Received: 6 July 2018; Accepted: 18 August 2018; Published: 21 August 2018

\begin{abstract}
Fruits of 240 Eucommia ulmoides Oliver individuals were collected from 12 different geographical regions across a wide area of China. The seed oil content ranged from $28.54 \%$ in Guilin and Lueyang to $31.35 \%$ in Chaoyang. Gas chromatography-mass spectrometry analysis of the seed oil revealed that linolenic acid (56.68-60.70\%), oleic acid (16.31-17.80\%), and linoleic acid (11.02-13.32\%) were the major components, and the oil showed good potential for the food and health care industries. Three levels (high, medium, and low) of linolenic acid and oil content were observed among the 12 populations according to principal component analysis. Canonical correspondence analysis showed that environmental factors had a large influence on oil content and fatty acids composition and explained $89.33 \%$ of the total variance. Latitude and precipitation were key environmental factors and were significantly correlated with the fatty acid composition of E. ulmoides seeds.
\end{abstract}

Keywords: Eucommia ulmoides seed; fatty acids; variation; geographical and climatic factors

\section{Introduction}

Plant seed oil contains saturated fatty acids (SFA) and unsaturated fatty acids (UFA), both of which play important roles in the regulation of human body functions. Unsaturated fatty acids are essential fatty acids with high nutritional and health care values, which show more beneficial health-related effects [1], while SFA may increase the risk of heart attack, diabetes, and cancer [2]. The pharmacological effects of fatty acids have attracted increasing research attention.

Eucommia ulmoides Oliver (Duzhong in China) (Eucommiaceae) is an important medicinal and woody oil species. It is endemic to China and is widely distributed from subtropical to temperate areas. The oil content of E. ulmoides seeds is approximately 35\%,63\% of which is unsaturated fatty acids, particularly $\alpha$-linolenic acid [3]. E. ulmoides seed oil possesses many pharmacological functions, such as anti-hypertensive effects, anti-oxidative effects, anti-inflammatory effects, immunity enhancement, and blood lipids regulation [4-7]. Recently, E. ulmoides seed oil has been listed as a new food resource, and related products with good nutrition and health value, such as edible oil and $\alpha$-linolenic acid soft capsules, have shown good market potentials.

Most previous studies of E. ulmoides seed oil have focused on extraction and determination methods, toxicology, pharmacology, the accumulation process, and related molecular mechanisms. Zhang et al. [8] determined fifteen fatty acid components of E. ulmoides seed oil by fraction chain 
length and mass spectrometry. $\mathrm{Xu}$ et al. [9] revealed the accumulation process of the main fatty acids in Eucommia seeds. Feng et al. [10] studied the molecular mechanism of the efficient accumulation of $\alpha$-linolenic acid in Eucommia seed oil. However, limited information is available on the variation in fatty acids composition and the effects of environmental factors on the fatty acids composition of E. ulmoides seed oils among different populations.

The objectives of this study were to analyze the variation in fatty acids composition and investigate the relationship between fatty acids composition, and then to assess the relationship between environmental factors and fatty acids composition among different populations.

\section{Materials and Methods}

\subsection{Plant Materials and Environmental Factors}

Fruits of 240 Eucommia ulmoides Oliver individuals were collected from 12 different geographical regions across a wide area of China (a range of $14^{\circ}$ latitude, $13^{\circ}$ longitude, and $675 \mathrm{~m}$ elevations) (Table 1) in October 2016. All of the trees had reached sexual maturity and were at least 20 years old; 20 individuals were sampled from each population and a minimum distance of $25 \mathrm{~m}$ was established between any two sample trees. The geographical locations of collection sites were determined using GPS, and consisted of latitude, longitude, and elevation. Climate data were obtained from the National Meteorological Data of China (http://data.cma.cn/) and the averages from 30 years were used. Climatic factors used included annual average relative humidity, average annual temperature, mean annual precipitation, and annual average sunshine duration (Table 1).

Table 1. Collection locations of E. ulmoides fruit and associated environmental factors.

\begin{tabular}{|c|c|c|c|c|c|c|c|}
\hline Location & $\begin{array}{l}\text { Latitude } \\
\text { (N) }\end{array}$ & $\begin{array}{l}\text { Longitude } \\
\text { (E) }\end{array}$ & $\begin{array}{c}\text { Elevation } \\
\text { (m) }\end{array}$ & RH (\%) & $\begin{array}{c}\text { Annual } \\
\text { Temp }\left({ }^{\circ} \mathrm{C}\right)\end{array}$ & Pre $(\mathrm{mm})$ & $\begin{array}{c}\text { Sunshine } \\
\text { Duration (h) }\end{array}$ \\
\hline Zunyi, Guizhou & $27^{\circ} 39^{\prime}$ & $107^{\circ} 08^{\prime}$ & 780 & 80 & 14.9 & 1005.8 & 1146.9 \\
\hline Guangyuan, Sichuan & $32^{\circ} 26^{\prime}$ & $106^{\circ} 50^{\prime}$ & 488 & 68 & 16.4 & 928.9 & 1348.0 \\
\hline Guilin, Guangxi & $25^{\circ} 29^{\prime}$ & $110^{\circ} 35^{\prime}$ & 390 & 75 & 19.1 & 1887.6 & 1549.5 \\
\hline Yuncheng, Shanxi & $35^{\circ} 01^{\prime}$ & $110^{\circ} 15^{\prime}$ & 369 & 66 & 12.9 & 489.9 & 2039.5 \\
\hline Luoyang, Henan & $34^{\circ} 37^{\prime}$ & $112^{\circ} 26^{\prime}$ & 146 & 69 & 13.9 & 568.4 & 2141.6 \\
\hline Haidian, Beijing & $39^{\circ} 57^{\prime}$ & $116^{\circ} 12^{\prime}$ & 47.5 & 55 & 12.8 & 557.5 & 2662.3 \\
\hline Chaoyang, Beijing & $39^{\circ} 53^{\prime}$ & $116^{\circ} 33^{\prime}$ & 45.2 & 57 & 12.4 & 559.2 & 2841.4 \\
\hline Anguo, Hebei & $38^{\circ} 42^{\prime}$ & $115^{\circ} 33^{\prime}$ & 34 & 64 & 12.8 & 468. & 1462.1 \\
\hline Xiangshui, Jiangsu & $34^{\circ} 08^{\prime}$ & $119^{\circ} 50^{\prime}$ & 5 & 75 & 14.2 & 1006.5 & 2399.7 \\
\hline
\end{tabular}

Abbreviations: RH: Annual average relative humidity; Annual Temp: Average annual temperature; Prec: Mean annual precipitation; Sunshine duration: Annual average sunshine duration.

\subsection{Seed Oil Extraction and Determination}

All fruits were preserved in a cool, dry place after harvesting until the pericarp was brown. The seed kernel was separated by peeling off the pericarp by hand and then oven dried at $45^{\circ} \mathrm{C}$. Seed oil was extracted and determined using the GB 5009.6-2016 Soxhlet extraction method. Ten grams of each seed sample was ground and packed with filter paper tube and put into a container, then petroleum ether (b.p. $60-90^{\circ} \mathrm{C}$ ) was added, and the seeds were subjected to water bath reflux extraction for $10 \mathrm{~h}$ at $65^{\circ} \mathrm{C}$. After extraction, residual petroleum ether was removed using rotary evaporator apparatus, and dried at $105{ }^{\circ} \mathrm{C}$ for $0.5 \mathrm{~h}$. The seed oil content was determined on the basis of dry matter and measurements.

\subsection{Fatty Acids Determination}

Firstly, $100 \mu \mathrm{L}$ of seed oil was diluted with $8 \mathrm{~mL} \mathrm{NaOH}$ : methanol solution $(0.5 \mathrm{~mol} / \mathrm{L})$ in a round flask with a condenser pipe and heated in a water bath at $90{ }^{\circ} \mathrm{C}$ for $10 \mathrm{~min} ; 7 \mathrm{~mL}$ of $14 \%$ 
$\mathrm{BF}_{3} /$ methanol $(v / v)$ solution was added and the mixture was held for $2 \mathrm{~min}$; next, $5 \mathrm{~mL}$ hexane was added and the mixture was held for $2 \mathrm{~min}$. The mixture was left to stand at room temperature $\left(25^{\circ} \mathrm{C}\right)$ to clarify. The fatty acids composition was identified and quantified using a Thermo Trace 1310 (Thermo Fisher, Waltham, MA, USA), a gas chromatograph unit equipped with an HP-88 capillary column $(60 \mathrm{~m} \times 0.25 \mathrm{~mm} \times 0.2 \mu \mathrm{m})$, and with a flame ionization detector (FID). Injection port temperature was set at $250{ }^{\circ} \mathrm{C}$, the split ratio was 100:1, the injection volume was $1 \mu \mathrm{L}$, the carrier gas was nitrogen, and the flow rate was $1 \mathrm{~mL} / \mathrm{min}$. The temperature program was as follows: the initial column temperature was $120^{\circ} \mathrm{C}$ for $1 \mathrm{~min}$, which was then increased at $10^{\circ} \mathrm{C} / \mathrm{min}$ to $175^{\circ} \mathrm{C}$, held for $10 \mathrm{~min}$, then increased at a rate of $5{ }^{\circ} \mathrm{C} / \mathrm{min}$ from $175^{\circ} \mathrm{C}$ to $210^{\circ} \mathrm{C}$ and held for $5 \mathrm{~min}$, and, finally, was heated at $10{ }^{\circ} \mathrm{C} / \mathrm{min}$ to $230^{\circ} \mathrm{C}$ and held again for $5 \mathrm{~min}$. The composition of fatty acids was identified by retention time and compared with known components from the database.

\subsection{Statistical Analysis}

The results are reported as mean \pm standard deviation (SD). ANOVA analysis and Duncan multiple comparisons were performed to examine significant differences of seed oil content and fatty acids composition between populations at $p<0.05$. Correlation analysis and principal component analysis (PCA) of oil and fatty acids of E. ulmoides seed were performed. These analyses were performed using SPSS19.0 (SPSS Science, Chicago, IL, USA). A canonical correspondence analysis (CCA) was conducted to determine to what extent the geographical and climatic factors affect fatty acids composition variation; fatty acids were the response variables, and the geographical and climatic factors were the explanatory variables. The analysis was conducted using the package vegan v.1.8-5 [11] in the $R$ version 2.5.0 statistical environment [12].

\section{Results and Discussion}

\subsection{Variation in Oil Content and Fatty Acids Composition of E. ulmoides Seeds}

The oil content and fatty acids composition of E. ulmoides seeds are shown in Table 2. For seed oil, the average amount of 240 individuals was $29.97 \%$ (Figure 1), the lowest value was found in Guilin (28.54\%) and Lueyang (28.54\%), which was significantly lower than that in Chaoyang $(31.35 \%)$, Haidian (30.80\%), and Luoyang (30.92\%) populations. Tang et al. [13] revealed a low amount of seed oil content (24.18-28.01\%) of E. ulmoides seed collected from different production areas, which may be related to the number of samples. High oil content populations can be applied to food industries.

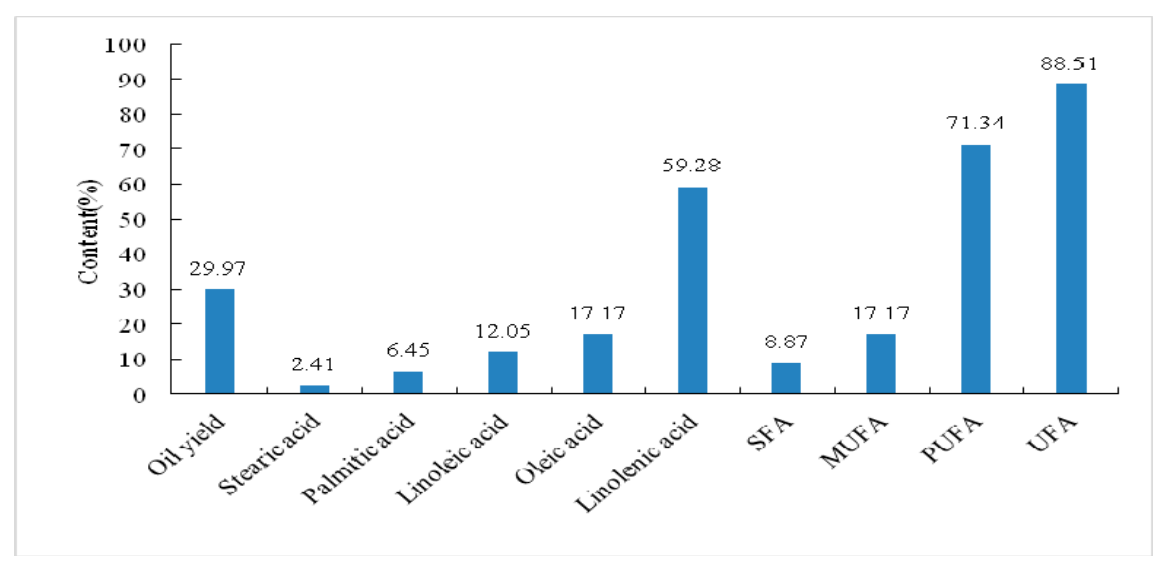

Figure 1. Average oil and fatty acids content of E. ulmoides seeds among 12 populations. SFA: saturated fatty acids; MUFA: monounsaturated fatty acid; PUFA: polyunsaturated fatty acid; UFA: unsaturated fatty acids. 
Table 2. Oil content and fatty acids composition of E. ulmoides seeds among 12 populations.

\begin{tabular}{cccccccc}
\hline Location & Oil Content/\% & Stearic Acid/\% & Palmitic Acid/\% & Linoleic Acid/\% & Oleic Acid/\% & Linolenic Acid/\% & UFA/SFA \\
\hline Zunyi & $28.80 \pm 2.60 \mathrm{bc}$ & $2.27 \pm 0.40 \mathrm{~cd}$ & $6.29 \pm 0.46 \mathrm{bc}$ & $12.63 \pm 1.26 \mathrm{ab}$ & $17.54 \pm 0.51 \mathrm{ab}$ & $58.71 \pm 1.08 \mathrm{bcd}$ & $10.44+0.88 \mathrm{a}$ \\
Lueyang & $28.54 \pm 1.94 \mathrm{c}$ & $2.38 \pm 0.31 \mathrm{c}$ & $6.29 \pm 0.58 \mathrm{bc}$ & $12.37 \pm 0.69 \mathrm{ab}$ & $16.31 \pm 1.04 \mathrm{~d}$ & $60.10 \pm 1.02 \mathrm{ab}$ & $10.26+0.58 \mathrm{a}$ \\
Guangyuan & $29.84 \pm 2.49 \mathrm{abc}$ & $2.54 \pm 0.41 \mathrm{abc}$ & $6.34 \pm 0.47 \mathrm{bc}$ & $12.32 \pm 1.62 \mathrm{ab}$ & $17.14 \pm 0.64 \mathrm{abc}$ & $59.24 \pm 2.24 \mathrm{abcd}$ & $10.03+0.72 \mathrm{a}$ \\
Guilin & $28.54 \pm 1.93 \mathrm{c}$ & $2.48 \pm 0.42 \mathrm{bc}$ & $7.00 \pm 0.35 \mathrm{a}$ & $13.32 \pm 1.93 \mathrm{a}$ & $17.53 \pm 1.07 \mathrm{ab}$ & $56.68 \pm 3.03 \mathrm{e}$ & $9.26+0.53 \mathrm{~b}$ \\
Yuncheng & $29.57 \pm 2.08 \mathrm{abc}$ & $2.37 \pm 0.27 \mathrm{c}$ & $6.27 \pm 0.40 \mathrm{bc}$ & $12.06 \pm 1.32 \mathrm{bc}$ & $17.15 \pm 0.67 \mathrm{abc}$ & $59.57 \pm 1.84 \mathrm{abc}$ & $10.32+0.70 \mathrm{a}$ \\
Shapingba & $30.26 \pm 1.59 \mathrm{abc}$ & $2.77 \pm 0.25 \mathrm{a}$ & $6.60 \pm 0.32 \mathrm{~b}$ & $12.42 \pm 1.46 \mathrm{ab}$ & $17.40 \pm 0.69 \mathrm{ab}$ & $58.15 \pm 2.24 \mathrm{cde}$ & $9.42+0.49 \mathrm{~b}$ \\
Cili & $30.38 \pm 2.01 \mathrm{ab}$ & $2.75 \pm 0.32 \mathrm{ab}$ & $7.03 \pm 0.36 \mathrm{a}$ & $11.99 \pm 1.58 \mathrm{bc}$ & $17.80 \pm 1.02 \mathrm{a}$ & $57.64 \pm 2.09 \mathrm{de}$ & $8.98+0.60 \mathrm{~b}$ \\
Luoyang & $30.92 \pm 2.191 \mathrm{a}$ & $2.27 \pm 0.31 \mathrm{~cd}$ & $6.35 \pm 0.48 \mathrm{bc}$ & $11.02 \pm 1.93 \mathrm{c}$ & $17.01 \pm 1.17 \mathrm{bcd}$ & $60.70 \pm 2.97 \mathrm{a}$ & $10.35+0.83 \mathrm{a}$ \\
Haidian & $30.80 \pm 2.101 \mathrm{a}$ & $2.27 \pm 0.41 \mathrm{~cd}$ & $6.16 \pm 0.42 \mathrm{c}$ & $11.48 \pm 1.25 \mathrm{bc}$ & $16.95 \pm 0.91 \mathrm{bcd}$ & $60.52 \pm 2.05 \mathrm{a}$ & $10.62+0.87 \mathrm{a}$ \\
Chaoyang & $31.35 \pm 2.061 \mathrm{a}$ & $2.34 \pm 0.43 \mathrm{~cd}$ & $6.44 \pm 0.51 \mathrm{bc}$ & $11.42 \pm 1.05 \mathrm{bc}$ & $16.62 \pm 0.82 \mathrm{~cd}$ & $60.53 \pm 1.53 \mathrm{a}$ & $10.19+1.05 \mathrm{a}$ \\
Anguo & $30.45 \pm 2.47 \mathrm{ab}$ & $2.46 \pm 0.39 \mathrm{c}$ & $6.31 \pm 0.53 \mathrm{bc}$ & $11.70 \pm 1.95 \mathrm{bc}$ & $17.06 \pm 1.01 \mathrm{abc}$ & $59.95 \pm 2.61 \mathrm{ab}$ & $10.21+1.07 \mathrm{a}$ \\
Xiangshui & $30.19 \pm 1.97 \mathrm{abc}$ & $2.07 \pm 0.29 \mathrm{~d}$ & $6.36 \pm 0.40 \mathrm{bc}$ & $11.93 \pm 1.23 \mathrm{bc}$ & $17.50 \pm 0.77 \mathrm{ab}$ & $59.63 \pm 1.65 \mathrm{abc}$ & $10.63+0.88 \mathrm{a}$ \\
$\mathrm{F}$ & $8.523^{* * *}$ & $4.340^{* * *}$ & $4.131 * *$ & $10.815 * *$ & $6.608^{* * *}$ & $3.990 * * *$ & $10.947 * * *$ \\
$p$ & 0.000 & 0.000 & 0.000 & 0.000 & 0.000 & 0.000 \\
\hline
\end{tabular}

The different lowercase letters in the same column indicate significant difference $(p<0.05) .{ }^{* * *}$ Very highly significant.

The composition of fatty acids in this study consisted of linolenic acid, oleic acid, linoleic acid, palmitic acid, and stearic acid, which are similar to those reported by Shu et al. [14] and Zhang et al. [15]. By multiple comparisons, significant differences in fatty acids composition of the seed oil existed among most regions. Among all fatty acids, linolenic acid was the most abundant, followed by oleic acid and linoleic acid. For linolenic acid, the lowest and the highest content were found in Guilin $(56.68 \%)$ and Luoyang $(60.70 \%)$, respectively; the content from the Guilin population was significantly lower than those from all other populations except Cili and Shapingba. The second most abundant fatty acid, oleic acid, varied from $16.31 \%$ in the Lueyang population to $17.80 \%$ in Cili. As the third most abundant fatty acid, linoleic acid ranged from $11.02 \%$ in Luoyang to $13.32 \%$ in Guilin. Palmitic acid, the fourth most abundant fatty acid, varied from $6.16 \%$ in Haidian to $7.03 \%$ in the Cili population; the contents in the Cili and Guilin populations were significantly higher than those from the other 10 populations. For stearic acid, the highest and the lowest values were found in Shapingba $(2.77 \%)$ and Xiangshui (2.07\%), respectively. The ratio of UFA/SFA ranged from 8.98 to 10.63 a higher ratio of UFA/SFA in human diets is considered beneficial for health.

E. ulmoides seed oils contained high concentrations of UFA (88.51\%), especially linolenic acid (59.28\%) (Figure 1), a known characteristic of E. ulmoides seed oil, and these results are similar to those reported by Jiao et al. [16]. The total amounts of polyunsaturated fatty acid (PUFA) and monounsaturated fatty acid (MUFA) were $71.34 \%$ and $17.17 \%$, respectively (Figure 1 ). $\alpha$-linolenic acid is an essential fatty acid, which can be metabolized into DHA and EPA [17]. A diet rich in PUFA is important for the structure and function of many membrane proteins, and MUFA has been shown to lower blood cholesterol levels [8]. These results suggest that E. ulmoides seed oils could be a better material for food and health care industries.

\subsection{Correlation among Oil Content and Fatty Acids of E. ulmoides Seeds}

Table 3 summarizes the results of the correlation analysis. Linolenic acid, the most abundant fatty acid of E. ulmoides seeds, was positively correlated with oil content and negatively correlated with the other four fatty acids, which may be related to its synthesis and conversion during seed development. Li et al. [18] reported that stearic acid, oleic acid, and linoleic acid can be converted into linolenic acid during seed development. Linoleic acid was negatively correlated with oil content and inversely associated with oleic acid. The correlation coefficients between oleic acid and palmitic acid, stearic acid were 0.247 and 0.165 , respectively. Palmitic acid was positively correlated with stearic acid and negatively correlated with oil content. These correlations between fatty acids can help us to understand the effects that selecting for a particular trait may have on other traits, which provides guidance for future genetic improvement. 
Table 3. Correlation among oil content and fatty acids of E. ulmoides seed.

\begin{tabular}{|c|c|c|c|c|c|c|}
\hline Traits & Oil Content & Palmitic Acid & Stearic Acid & Oleic Acid & Linoleic Acid & Linolenic Acid \\
\hline oil content & 1 & & & & & \\
\hline palmitic acid & $-0.137 *$ & 1 & & & & \\
\hline stearic acid & 0.019 & $0.388^{* *}$ & 1 & & & \\
\hline oleic acid & -0.087 & $0.247^{* *}$ & $0.165^{* *}$ & 1 & & \\
\hline linoleic acid & $-0.232 * *$ & 0.111 & -0.014 & $0.330^{* *}$ & 1 & \\
\hline linolenic acid & $0.229^{* *}$ & $-0.485^{* *}$ & $-0.310^{* *}$ & $-0.705^{* *}$ & $-0.809^{* *}$ & 1 \\
\hline
\end{tabular}

\subsection{Principal Component Analysis of Oil and Fatty Acids of E. ulmoides Seeds}

Principal component analysis (PCA) was applied to determine the most significant characteristics of the data set. Two principal components were extracted by the PCA and explained the highest variation in the data set (Table 4). The first PC (PC1) explained $58.983 \%$ of the total variation and showed a positive correlation with linoleic acid, palmitic acid, oleic acid, and stearic acid, and a strong negative correlation with linolenic acid. The second PC (PC2) explained $22.988 \%$ of the total variation and was positively correlated with oil content.

Table 4. The principal component analysis (PCA) of oil content and fatty acids among different populations.

\begin{tabular}{ccc}
\hline Component & PC 1 & PC 2 \\
\hline Linolenic acid & -0.994 & -0.048 \\
Oleic acid & 0.668 & 0.316 \\
Linoleic acid & 0.836 & -0.511 \\
Palmitic acid & 0.82 & 0.397 \\
Stearic acid & 0.621 & 0.466 \\
Oil content & -0.565 & 0.801 \\
Eigenvalues & 3.539 & 1.379 \\
Contributive percentage (\%) & 58.983 & 22.988 \\
\hline
\end{tabular}

According to the scatter plots constructed by PC1 and PC2 (Figure 2), the oil content and fatty acids composition of E. ulmoides seeds of different groups were greatly affected by geographical distribution, especially the Cili, Guilin, Lueyang, Shapingba, and Zunyi populations. The Chaoyang, Haidian, and Luoyang populations were grouped together, with all of them showing high linolenic acid content and oil content. The Guangyuan, Yuncheng, Anguo, and Xiangshui populations were grouped together, with all of them having medium linolenic acid content and oil content.

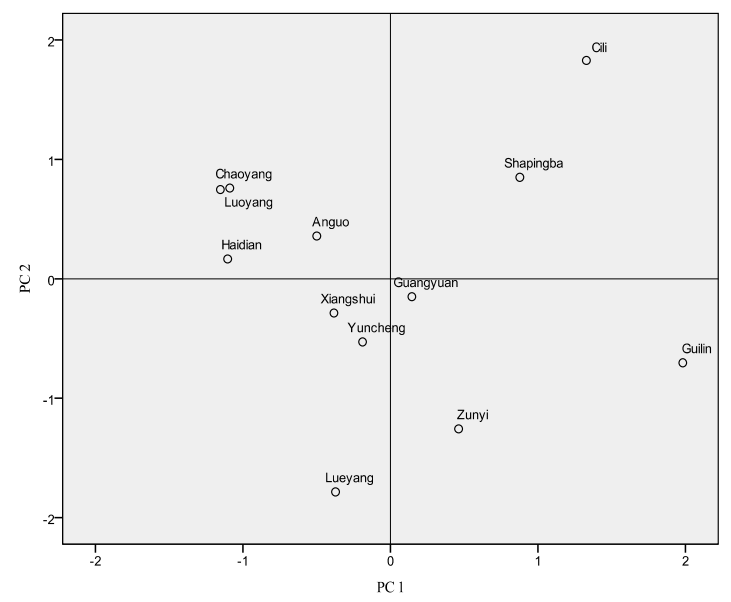

Figure 2. The relationship between different E. ulmoides populations based on PC1 and PC2. 


\subsection{Effect of Geographical and Climatic Factors on Seed Oil and Fatty Acid Variation}

The fatty acids composition of plant seed oil can be affected by genetic, geographical, and climatic factors, as well as their interactions [19]. Many studies have shown that environmental factors, such as precipitation, sunshine duration, elevation, and temperature, strongly affect fatty acid content [20,21]. Yao et al. [20] reported that in Camellia meiocarpa Hu. (Camellia L.), palmitic acid content was positively correlated with annual sunshine duration, and stearic acid content was significantly positively correlated with annual precipitation. In soybean seeds, the linoleic and linolenic acid contents decreased as the temperature increased, whereas the oleic acid content increased [22]. In Sapindus spp. (Sapindaceae) seed oil, C16:0 was positively correlated with maximum temperature, C20:1 was significantly correlated with elevation, and C18:2 was sensitive to the interaction between maximum temperature and elevation. Precipitation was another important factor that was significantly correlated with C20:0 [21]. To date, how the fatty acids composition of E. ulmoides seeds is affected by geographical and climatic factors has not been clearly studied. Hence, CCA analysis was employed in this study for the first time to assess to what extent environmental factors influence the variation of fatty acids of E. ulmoides seed oils.

As shown in Table 5, all geographical and climatic factors were incorporated in the CCA analysis. The canonical axes explained $89.33 \%$ of the total variation in oil content and fatty acids composition. The first two axes explained $78.20 \%$ of the total variance $(89.33 \%)$. The first axis of the CCA was predominantly positively correlated with latitude, annual average sunshine duration, and longitude, and negatively associated with mean annual precipitation, average annual temperature, and annual average relative humidity. The second axis was positively correlated with elevation.

Next, forward direction selection was carried out to remove redundant variables, and the CCA model was simplified for all factors and only climate factors and only key environmental factors in the CCA model were selected by ANOVA analysis (Table 6). In the simplified 'all factors' model, latitude significantly affected variation in fatty acids composition, explaining $52.00 \%$ of the total variance $(p<0.001)$. Elevation explained $26.69 \%$ of the total variance and was significant $(p<0.05)$. In the simplified 'climate factors' model, mean annual precipitation explained $51.88 \%$ of the total variance and was very highly significant $(p<0.001)$. No significant effects of the interactions between environmental factors were found.

A triplot reflecting oil content and fatty acids variation in relation to environmental factors was constructed based on the CCA analysis (Figure 3). Latitude was positively correlated with linolenic acid and precipitation was another important factor that was significantly correlated with oleic acid. Oil content and other fatty acids showed general sensitivity to the selected environmental factors. $\mathrm{Yu}$ [23] found that the epoxyeicosatrienoic acid content of E. ulmoides seeds was positively correlated with annual temperature and was negatively correlated with longitude; no other correlation between environmental factors and other fatty acids was observed. In other high linolenic acid plants, such as Perilla frutescens and Linum usitatissimum, linolenic acid content was significantly correlated with cold environment by comparing different planting areas [13].

The variation of fatty acids composition in E. ulmoides seed is largely controlled by environmental and genetic factors, but it has not been ascertained which have a greater effect. Additional studies to investigate the effects of genotype and the interactions between environmental and genetic factors on the fatty acids composition of E. ulmoides seeds would be helpful for the selection of genotypes containing useful fatty acids. 


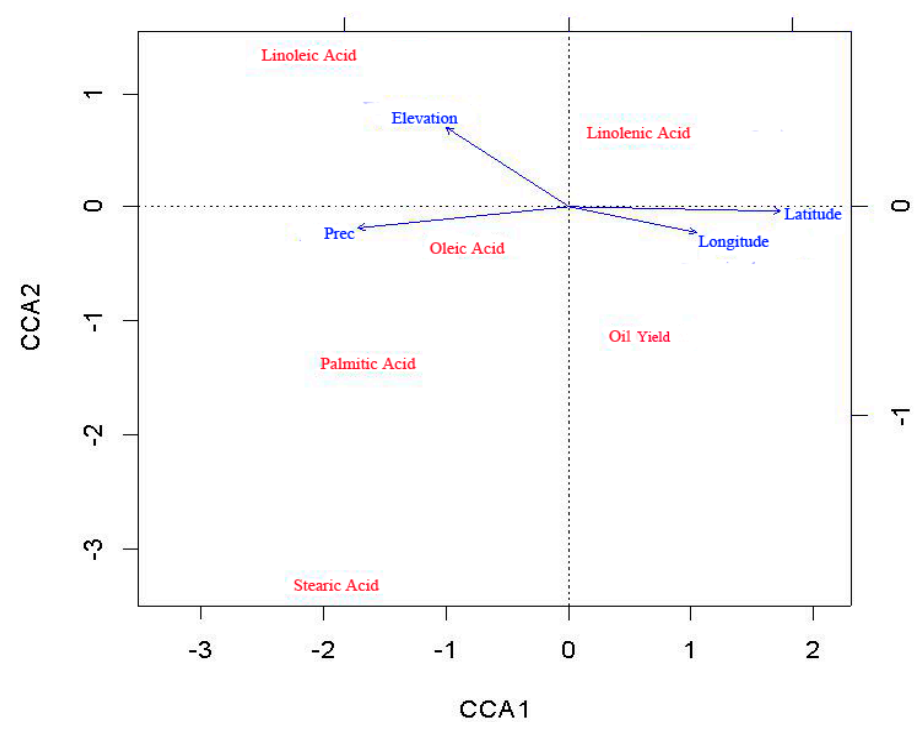

Figure 3. Triplot of oil and fatty acids variation in E. ulmoides seeds with environmental factors.

Table 5. Results of canonical correspondence analysis of fatty acid content of E. ulmoides seed.

\begin{tabular}{ccc}
\hline & CCA1 & CCA2 \\
\hline & Statistics & \\
\hline Eigenvalue & 0.0005146 & 0.0001625 \\
Proportion Explained & 0.5942700 & 0.1876800 \\
Cumulative Proportion & 0.5942700 & 0.7819500 \\
Total inertia (variance explained \%) & $0.0007735(89.33 \%)$ & \\
\hline Intraset correlation coefficients between the CCA axes and the environmental variables Terms \\
\hline Latitude & 0.9336 & -0.04298 \\
Longitude & 0.566 & -0.22045 \\
Sunshine duration & 0.7412 & -0.10866 \\
Prec & -0.9256 & -0.15715 \\
Relative humidity & -0.7387 & 0.05606 \\
Annual Temp & -0.8873 & -0.35276 \\
Elevation & -0.5378 & 0.67554 \\
\hline
\end{tabular}

Table 6. ANOVA of key factors in the canonical correspondence analysis (CCA) model.

\begin{tabular}{|c|c|c|c|c|c|c|c|}
\hline \multirow{2}{*}{ Explanatory Variable } & \multirow{2}{*}{ Variance Explained \% } & \multicolumn{3}{|c|}{ Model } & \multicolumn{3}{|c|}{ By Terms } \\
\hline & & Chi-Square & F & $\operatorname{Pr}(>F)$ & Chi-Square & F & $\operatorname{Pr}(>F)$ \\
\hline Environmental factors & $89.33 \%$ & 0.00077348 & 4.7837 & 0.006 ** & - & - & - \\
\hline Climate factors & $75.06 \%$ & 0.0006499 & 5.2658 & $0.001 * * *$ & - & - & - \\
\hline Prec & $51.88 \%$ & 0.00044921 & 10.781 & $0.001^{* * *}$ & 0.00044921 & 10.781 & $0.001^{* * *}$ \\
\hline Latitude & $52.00 \%$ & 0.00045023 & 10.832 & $0.001^{* * *}$ & 0.00045023 & 10.832 & $0.001^{* * *}$ \\
\hline Longitude & $23.13 \%$ & 0.00020028 & 3.0091 & 0.055 & 0.00020028 & 3.0091 & 0.055 \\
\hline Elevation & $26.69 \%$ & 0.00023112 & 3.641 & $0.033 *$ & 0.00023112 & 3.641 & $0.033 *$ \\
\hline
\end{tabular}

*** Very highly significant, ${ }^{* *}$ Highly significant, ${ }^{*}$ Significant.

\section{Conclusions}

Our results elucidated geographical variation of oil content and fatty acids composition of E. ulmoides seed, and it will be useful for E. ulmoides germplasm resources collection and utilization. Moreover, the variation of oil content and fatty acids composition may facilitate the breeding of new 
E. ulmoides lines for nutritional and medical uses. Linolenic acid was positively correlated with oil content but inversely correlated with other fatty acids. Furthermore, three levels (high, medium, and low) of linolenic acid and oil content types among 12 populations were determined. Environmental factors explained $89.33 \%$ of the total variation in oil content and fatty acids composition according to CCA analysis. The greatest influences on oil and fatty acids composition were latitude and precipitation, which accounted for $52.00 \%$ and $51.88 \%$ of the total variance, respectively. Linolenic acid and oleic acid showed environmental sensitivity, while oil content and other fatty acids were less sensitive to environmental factors, which may be affected more by genotype. Furth research should focus on the effects of genotype and the interactions between environmental and genetic factors on oil content and fatty acids composition of E. ulmoides seeds.

Author Contributions: Q.D. and H.D. conceived and designed the study; Q.D., L.W., P.L., and J.Q. collected samples and performed the experiments; Q.D. and C.S. analyzed data; Q.D. wrote the paper; H.D. and Z.S. contributed to writing the paper.

Funding: This research was funded by the National Key R\&D Program of China (2017YFD0600702).

Acknowledgments: We thank Bing $\mathrm{Xu}$, Feng He, and Lili Zhu for sample collecting.

Conflicts of Interest: The authors declare no conflict of interest.

\section{References}

1. Aronson, W.J.; Glaspy, J.A.; Reddy, S.T.; Reese, D.; Heber, D.; Bagga, J. Modulation of omega-3/omega-6 polyunsaturated ratios with dietary fish oils in men with prostate cancer. Urology 2001, 58, 283-288. [CrossRef]

2. Iso, H.; Sato, S.; Umemura, U.; Kudo, M.; Koike, K.; Kitamura, A. Linoleic acid, other fatty acids, and the risk of stroke. Stroke 2002, 33, 2086-2093. [CrossRef] [PubMed]

3. Duan, X.H.; Deng, Z.Y.; Zhu, D. Fatty acid and amino acid composition of Eucommia ulmoides Oliver seeds. Food Sci. 2010, 31, 214-217.

4. Berry, E.M.; Hirsch, J. Does dietary linolenic acid influence blood pressure? Am. J. Clin. Nutr. 1986, 44, 336. [CrossRef] [PubMed]

5. Deyama, T.; Nishibe, S.; Nakazawa, Y. Constituents and pharmacological effects of Eucommia and Siberian ginseng. Acta Pharmacol. Sin. 2001, 22, 1057-1070. [PubMed]

6. Xiang, Z.G.; Li, X.H. Antioxidant activity in vitro of seed oil from Eucommia ulmoides Oliver key fruits. Food Sci. 2011, 32, 133-136.

7. Ren, J.; Yang, Z.H.; Zheng, S.X.; Hu, K. Studies on in vitro anti-inflammatory mechanism of $\alpha$-linolenic acid. J. Yunnan Univ. 2009, 31, 419-426.

8. Zhang, L.X.; Ji, X.Y.; Tan, B.B.; Liang, Y.Z.; Liang, N.N.; Wang, X.L.; Dai, H. Identification of the composition of fatty acids in Eucommia ulmoides seed oil by fraction chain length and mass spectrometry. Food Chem. 2010, 121, 815-819. [CrossRef]

9. Xu, Y.R.; Zhang, J.J.; Li, Q. Research on the accumulation process of main fatty acids in Eucommia seeds. Chin. Pharm. J. 2016, 51, 1648-1651.

10. Feng, Y.Z.; Wang, L.; Fu, J.M.; Wuyun, T.N.; Du, H.Y.; Tan, X.F.; Zou, F.; Li, F.D. Transcriptome sequencing discovers genes related to fatty acid biosynthesis in the seeds of Eucommia ulmoides. Genes Genom. 2016, 38, 275-283. [CrossRef]

11. Oksanen, J.; Kindt, R.; Legendre, P.; O’Hara, B. Vegan: Community Ecology Package; R Foundation for Statistical Computing: Vienna, Austria, 2007.

12. R Development Core Team. R: A Language and Environment for Statistical Computing; R Foundation for Statistical Computing: Vienna, Austria, 2007.

13. Tang, C.Q.; Shen, Z.P. GC-MS analysis of linolenic acid content and oil yields in seed oils of Eucommia ulmoides, Perilla frutescens and Linum usitatissimum growing in different areas. J. Anhui Agric. Sci. 2016, 44, 98-100.

14. Shu, X.M.; Li, J.X.; Wang, X.Y.; Yang, J.J.; Yuan, Q.H. Optimization of subcritical extraction of Eucommia ulmoides seed oil and its fatty acid composition analysis. China Oils Fats 2015, 40, 15-18. 
15. Zhang, P.P.; Tang, C.Q. GC-MS analysis of fatty acids composition and $\alpha$-linolenic acid content of Eucommia ulmodies seeds from different growing areas with a direct methyl-ester method. Cereals Oils 2016, 29, 53-55.

16. Jiao, H.L.; Liu, Y.L.; Zhang, D.D. Qualities of Eucommia ulmoides seeds oils from different areas and oil extraction techniques. Cereals Oils 2015, 28, 53-57.

17. Wu, L.Y.; Yang, W.G.; Huang, Q.; Yu, J.; Chen, G.X.; Ma, C.J. Separation of unsaturated fatty acid from Eucommia seed oil and the analysis of its $\alpha$-linolenic acid content. J. Food Saf. Qual. 2013, 4, 1393-1400.

18. Li, T.Z.; Du, H.Y.; Liu, P.F. Differential expression of related genes of $\alpha$-linolenic acid biosynthetic in Eucommia ulmoides. Nonwood For. Res. 2013, 3, 25-31.

19. King, A.J.; Montes, L.R.; Clarke, J.G.; Itzep, J.; Perez, C.A.A.; Jongschaap, R.E.E.; Visser, R.G.F.; van Loo, E.N.; Graham, I.A. Identification of QTL markers contributing to plant growth, oil yield and fatty acid composition in the oil seed crop Jatropha curcas L. Biotechnol. Biofuels 2015, 8, 160. [CrossRef] [PubMed]

20. Yao, X.H.; Wang, K.L.; Huang, Y.; Ren, H.D. Analysis and evaluation on variation characteristics of oil content and fatty acid composition of Camellia meiocarpa populations. For. Res. 2013, 26, 533-541.

21. Sun, W.C.; Jia, L.M.; Xi, B.Y.; Wang, L.C.; Weng, X.H. Natural variation in fatty acid composition of Sapindus spp. seed oils. Ind. Crops Prod. 2017, 102, 97-104. [CrossRef]

22. Medic, J.; Atkinson, C.; Hurburgh, C.R. Current knowledge in soybean composition. J. Am. Oil Chem. Soc. 2014, 91, 363-384. [CrossRef]

23. Yu, J. Germplasm Resource of Eucommia ulmoides Oliver and Fruits Quality Evaluation. Ph.D. Thesis, Northwest A \& F University, Yangling, China, 2015; pp. 55-64.

(C) 2018 by the authors. Licensee MDPI, Basel, Switzerland. This article is an open access article distributed under the terms and conditions of the Creative Commons Attribution (CC BY) license (http:/ / creativecommons.org/licenses/by/4.0/). 